\title{
Could Tourism Carrying Capacity Be A Useful Tool For Adapting To Climate Change?
}

\author{
Alexandre MAGNAN, Institute for sustainable development and international relations (IDDRI), \\ France, alexandre.magnan@iddri.org \\ Virginie DUVAT, LIENSs (Littoral, Environnement, SociétéS), UMR Université de la Rochelle-CNRS \\ 6250, France,virginie.duvat@univ-Ir.fr
}

\begin{abstract}
This paper focuses on coastal areas and aims at providing a first reflection on the potential role of the tourism carrying capacity approach (TCC) in the context of adaptation to climate change (ACC). Could TCC be seen as a pragmatic and already available tool for starting implementing ACC?
\end{abstract}

Keywords: tourism carrying capacity, adaptation to climate change.

\section{Introduction}

Adaptation to climate change (ACC) is now acknowledged as being one of the most crucial challenges for coastal areas in the next decades. It is also largely recognised that ACC is a multi-scalar issue. However, one great problem societies have to deal with is that of climatic uncertainties. Indeed, despite global climate models are until now unable to provide precise insights regarding climate change impacts at a local scale. This inability is due to numerous constraints resulting from the modelling exercise, the potential responses of ecosystems to climate stimuli and of human societies to changing conditions. Consequently, it must be accepted that at least for the next decade, uncertainties will continue to impose strong constraints to local decision-makers and private operators. In parallel, scientists have also highlighted that climate change is now partly irreversible (Solomon et al., 2009). It is thus unproductive to wait for more precise scientific knowledge on the expected impacts to start acting in favour of adaptation, and one of our underlying hypothesis is here that 'starting by doing well what we currently badly do' is a first step. Climate change will indeed essentially exacerbate existing problems such as environmental degradations and societal inequalities and yet, trying to solve these current problems should be seen as a pragmatic manner to make societies more robust facing changing conditions.

This posture thus emphasises the crucial role of current tools designed for accompanying territorial management processes. This is the case of the tourism carrying capacity (TCC) which goal is precisely to provide pragmatic recommendations for local and regional territorial management. Based upon the assessment of both environmental vulnerability and societal acceptability of tourism flows, it aims at drawing up a diagnosis of the situation in order to allow decision-makers to have a clear vision of real pressures and leverages they have to cope with. Two main benefits of the TCC approach seem important regarding the adaptation challenge. Firstly, it promotes a global and systemic understanding: 'global' because it takes into account all the processes that underlie territorial dynamics (economic challenges, social stability, environmental degradation and preservation, transportation, etc.); 'systemic' because it also takes into account the interactions between these processes (synergies and conflicts). Secondly, TCC allows describing destination's features with indicators which are useful for quantifying the ratio between the weaknesses and the 
strengths of the tourism destination in front of perturbations (natural or not, gradual or not). This quantified index is often criticized in the scientific and grey literature as its detractors argue that territorial dynamics cannot be reduced to one single number. What we defend in this paper is that beyond the numerical value in itself, TCC index must be considered as an order of magnitude. So, its regular monitoring is more interesting than a one-shot assessment. Indeed, the decrease, the constancy or the increase of this TCC level respectively mean that the territory is progressively saturating, stabilizing or developing. It thus gives precious insights to decision-makers both to know which strategy to promote for the future and upon which weaknesses and strengths this strategy should be built. TCC could then be considered as a tool for accompanying the ACC process.

This short text is divided into two parts, reminding the underlying principles of the TCC approach and describing the common features and main differences between TCC and ACC.

\section{TCC approach: principles, framework and methodological aspects}

Albeit the 'carrying capacity' idea had been introduced by T. Malthus, the concept was scientifically formalized at the beginning of the $20^{\text {th }}$ century in the field of ecological studies, and later in human recreational concerns. Even if TCC studies probably began during the 1930's (O'Reilly, 1986; Saveriades, 2000), they were principally developed in the 1960's in the national parks of the United States of America (McCool and Lime, 2001; Manning et al., 2002). However, what we draw up today is that after several decades of experimentation, the concept itself has not evolved a lot and criticisms are still approximately the same (Deprest, 1997; Clarke, 2002). As V. Duvat wrote: "the concept of tourism carrying capacity disturbs general scientific thinking by disrupting the usual points of reference ${ }^{1}$. That explains why this concept sparks off two extreme reactions within the scientific community: support or rejection"2 $(2007,265)$.

Here, we won't focus on these controversies, but we must point out that even if we admit some limitations of the TCC approach, we believe in its usefulness for dealing with territorial development issues.

The goal of the first part is to highlight that the TCC approach both leans on tangible data collection and is local scale-based.

\subsection{Definition and main goals}

Numerous definitions of TCC exist nowadays which all highlight its global and systemic nature, at the crossroads of environmental, economic, socio-cultural, infrastructural and political dimensions of a tourism destination. In general, TCC is viewed as the 'maximum number of visitors' an area can host without damaging effects on the environment and the society. The concept is however far from just being a number issue. It indeed "means that tourism economic growth has to be responsible towards local society and its cultural values, and compatible with the preservation and improvement of the local natural environment and with the conservation of the local traditional economic activities" (Marzetti and Mosetti, 2005: 2). According to this view, TCC is considered as a tool for implementing sustainable development, and it is underlined by three major keywords: 'saturation', 'limit' and 'threshold'.

\footnotetext{
${ }^{1}$ TCC requires a global and systemic approach (see below), whereas classical scientific approach leans on disciplinary fields.

${ }^{2}$ Original quotation: "La capacité de charge touristique dérange l'ordre établi des questionnements scientifiques, elle bouleverse des repères et c'est certainement la raison pour laquelle elle suscite principalement deux types de réactions au sein des milieux de la recherche : l'adhésion ou la critique".
} 
Trying to understand what these words signify in a tourism context, S.F. McCool and D.W. Lime (2001) talked about the "limits of acceptable change" and defined TCC as "the amount of change acceptable". Acceptability refers to many dimensions, from environmental assets, dynamics and equilibrium to anthropogenic features. Then, the territory's TCC depends on the ability of the environment to absorb a certain amount of tourism flows without irreversible deteriorations, as well as on the ability of local population, institutions and economy to deal with growing tourism without affecting their fundamental values (identity, culture, independence...). In theory, an overflow of TCC leads to serious environmental degradations and/or to a decline in the local quality of life (hosts' viewpoint) and/or to a decline in the attractiveness of the destination (tourists' viewpoint).

Each dimension of TCC (environmental, socio-cultural...) relates back to a specific form of saturation and to different kinds of thresholds. And that is when the combination of these potential thresholds is reached - because of 'too much'3 tourism flows - that one can conclude to the exceeding of the global TCC. However, it is not likely that all these thresholds are reached together at the same time, and field reality shows a lot of intermediate situations before saturation situations. It also means that as long as all the thresholds are not overflowed, some room for manoeuvre still exists.

Trying to analyse the TCC process constitutes a major issue for destinations' management as it allows evaluating the distances from all the thresholds. Thus, TCC must firstly be considered as a tool for accompanying decision-making and global management of tourism destinations (Pereira da Silva, 2002; Duvat, 2008; Pottier et al., 2009). And its truly relevance leans on the fact that TCC studies rely on various diagnosis respectively concerning environment, transport networks, local tourism activities, of hosts' perceptions on tourism, tourists' perceptions, rules and regulations.... This 'data emphasising' is complex and requires a structured framework to be achieved.

\subsection{General framework for studying TCC}

Different authors have proposed interesting approaches for measuring TCC (see for example: Cazes-Duvat and Pesme, 2002; Saveriades, 2000; Cocossis et al., 2001; Pereira da Silva, 2002: Pottier et al., 2009). A synthesis of some of these approaches lead to distinguish 3 principal steps.

\subsubsection{Defining a territorial project and the limits of acceptable changes (Step 1)}

Firstly, we can assume with I. Seidl and C.A. Tisdell (1999) that the concept of TCC can be operational only if the ultimate objectives of, the territorial components involved in and the stakeholders concerned by the analysis of TCC are clearly identified at the beginning of the study. The first step then consists in a large consultation of the destination's stakeholders (authorities, economic players and populations) about their expectation regarding tourism development and about the fundamental shared values (cultural, economic, environmental...) they want to preserve. This step defines the limits of acceptable changes and highlights the fact that any intrinsically or a priori TCC can exist.

\footnotetext{
${ }^{3}$ 'Too much' is an often utilized expression in the literature. However, several authors remind that 'saturation' is not only due to the simple number of tourists, but also to their practices and intentions (Manning et al., 2002; Duvat, 2007).
} 


\subsubsection{The scientific contribution: assessing the global vulnerability (step 2)}

The second step aims at characterizing from a scientific perspective the current states of the environment and living conditions, and the positive and negative impacts of tourism. This kind of approach is usually called 'vulnerability'.

Vulnerability can be considered as the susceptibility of a system to be disturbed by endogenous or exogenous pressures. In the arena of natural hazard science, P. Blaikie, T. Cannon, I. Davis and B. Wisner have shown that "vulnerability is rooted in social processes and underlying causes which may ultimately be quite remote from the disaster event itself. (...) A disaster is the intersection of two opposing forces: those processes generating vulnerability on one side, and physical exposure to a hazard on the other" (Blaikie et al., 1994, 22). This conception also fits with non-natural stresses such as in our case tourism saturation. And finally, vulnerability assessment must be seen as a monitoring tool of the strengths and weaknesses of a territory in face of disturbing factors (Magnan, 2009).

In the context of TCC assessment, the vulnerability approach can be schematically reduced to two main categories. On the one hand, the environmental vulnerability focuses on the physical impacts of tourism at the destination. On the other hand, the human vulnerability deals with the anthropogenic issues (socio-cultural, economic and tourism) and focuses on the impacts of tourism both on the local quality of life and on the tourism product.

Concretely, vulnerability assessments lean on the identification of a panel of indicators aimed at quantifying the features of the territory and its dynamics. The results obtained can be synthesised on maps that can be used as triggers to enhance discussions.

\subsubsection{Identification of TCC level (step 3)}

At this stage, a large consultation must be operated through interviews with local authorities and economic players (tourism operators, mainly) and questionnaires among local population and tourists. The aim is to quantitatively determine the environmental and anthropogenic thresholds that are acceptable. Based upon the scientific results emphasised in step 2, a debate has to be opened in order to define a compromise on a shared acceptability of the previous thresholds.

The following step consists in the formulation of recommendations for developing tourism in harmony with the territorial project defined between steps 1 and 3 . These recommendations are relevant on the condition that they are compatible with the future that local stakeholders want to reach. Then, the goal of TCC is not in itself to achieve sustainable development, but rather to achieve a chosen and realistic territorial project. Yet, our view is that ACC relies on the same frame of mind (Magnan, 2010a).

\subsection{TCC assessment as a part of a more general process}

The issue of the numerical value (often called ironically the 'magic number'), must be replaced in the context of tourism destinations development and evolution. Our view is that the TCC synthetic index highlighted after the 3 previous steps does not represent a precise level of TCC, but an order of magnitude. Firstly, this means that the number is not important in itself (it is not 'magic'), but in the order of magnitude it refers to. Secondly, as systems inevitably evolve, it is necessary to consider this index not as a fixed value, but as an evolving one. TCC at time $t$ cannot be the same than at time $t_{+1}$, and then TCC index must be seen as a cursor or a 'tracer' of the initial territorial project's implementation. The relevance 
of the TCC approach thus leans on the monitoring of its evolution. The higher the TCC, the more management practices are efficient, the less the destination is vulnerable to a growing tourism activity.

\section{How TCC could be useful for ACC?}

TCC could be potentially useful for ACC because of some shared features. This induces that implementing a TCC analysis allows emphasising the basic data and territorial dynamics needed for identifying ACC's room for manoeuvre, and furthermore building a realistic adaptation strategy. But one must be aware about the preconditions for favouring these synergies between TCC and ACC: basic differences indeed exist between them which are related both to their own nature and to the temporal scales they concern.

\subsection{Common features between TCC and ACC}

\subsubsection{TCC \& ACC require a systemic and global approach}

As showed previously, the relevance of the TCC approach leans on the necessity to look at the environmental and anthropogenic features of a territory and at their interactions. Sectorspecific analysis only focused on the tourism activity could lead to a misunderstanding of the real stakes of tourism development. Yet, studying the relationship between tourism and climate change also requires considering the tourism territory as a whole rather than focusing exclusively on the tourism sector itself (Duvat and Magnan, 2009; Magnan, 2010b). Tourism activity is for example known for being a 'stimulator of the local economy' and its economic, environmental and socio-cultural impacts transcend the specific location of tourism activities (e.g. a small coastal fringe or an inland site).

Here, we get close to the larger question of the implementation of sustainable development. This leads us to say that climate change, even if it poses new problems for human societies (namely the rhythm of changes), certainly constitutes one of the major opportunities for modern societies to implement sustainable actions and strategies. Typically the 'no regrets' options are part of this idea: the restoration of mangroves on tropical coasts is both an act of sustainable development (in favour of local ecosystems and cultures) and a mean to fight against the potential consequences of climate change (buffer role against waves). And yet, the global and systemic knowledge that is needed to implement no regret actions requires local authorities and stakeholders (not only from the tourism sector) to get the right information. 'Right' information signifies interconnected data on the impacts and challenges of the tourism activity regarding the whole dynamics of the destination (demography, economy, living conditions...). This is precisely the goal of TCC analysis which thus constitutes a relevant starting point for local destinations to implement an ACC process.

\subsubsection{TCC \& ACC are context-specific}

The necessity to develop a global and systemic approach induces to be context-specific. Indeed, beyond some general mechanisms which are common from one destination to another, each context presents specific features which combinations explain why TCC levels vary from one place to another.

In parallel, the scientific literature on ACC shows that in its implementation phase (preparation of a strategy, identification of concrete measures...), adaptation process is also necessarily specific to a given territory (Smit and Wandel, 2006). In the ACC arena, a 
common mistake consists in considering 'good practices' as experiences that can be applied to other contexts without any modification, rather than as simple examples of the implementation of general principles. This is also true for TCC experiences.

\subsubsection{TCC \& ACC are evolving}

Finally, as TCC and ACC are context-specific and as territories are unavoidably changing, both TCC thresholds and ACC options must be conceived as necessarily evolving.

The IPCC emphasizes this evolving conception as it defines ACC as an "adjustment of natural or (...) human systems facing a new environment or a changing environment." The concept of adjustment refers to the mechanism of flexibility, which allows the system to modify its structures and modes of operation and its development strategies according to perturbations that occur. Whether these disturbances are punctual or more gradual, there must be various forms of adaptation that include both anticipation strategies (prior to the disturbance) and reactive ones (following the event). Thus, adaptation should not be seen as a picture of the system at a given time (is it suitable or not?), but rather as a continuous and dynamic process by which the system adapts. A form of adaptation at a given moment and in a specific context is therefore likely to change over time. In parallel, as previously demonstrated, the TCC level must be understood as an evolving 'cursor' providing local authorities and stakeholders with keys for making readjustments. In that sense, TCC is a tool - probably among others - for implementing the adaptation process.

\subsection{Key differences between TCC and Adaptation}

Two main differences can be emphasized here which refer to the distinctive natures of TCC and ACC, and to the temporal and spatial scales they concern.

\subsubsection{Different natures: TCC is a tool, $A C C$ is a concept}

Referring to previous developments, we can now argue that TCC is primarily a tool aiming at describing a situation and its evolution at the crossroads of scientific realities (impacts of tourism on the environment, on the society and on the territorial dynamics) and social and institutional judgements concerning the limits of acceptable change. Assessing and monitoring a TCC index then allows identifying the current and potential thresholds. However, it does not constrain the political choices to reduce or increase the number of visitors or to promote another distribution of tourists at the local destination (Duvat, 2008). The TCC conclusions are solely indicative.

On the other hand, ACC is not a descriptive tool, but both a result of and a goal for territorial policies. We understand here adaptation as a three-dimension topic (Magnan, 2010a): a process, which refers to the mechanisms of adaptation (on a theoretical point of view); a state, which refers to the forms of adaptation (what is adaptation on the field?); and a strategy, which refers to the policy dimension. ACC is a combination of these three dimensions, which are the results of societal, environmental and political choices.

This is paradoxically because TCC and ACC are different in nature that TCC can be useful for adapting to climate change. Societal, environmental and political choices indeed need to be supported by scientific descriptions of the real pressures and by the evaluation of what is really at stake. TCC study provides such inputs. 


\subsubsection{Different temporal focuses: TCC is short-time constrained, ACC is multi- temporal}

TCC study is necessarily contained in time and then dependant on a limited temporal scale. Tourism activity is a fast-growing activity and the related changes on the local environment and on the local economy and society are themselves rapid. Then, TCC study can be useful but as the conclusions of one survey are intrinsically obsolete, they must be repeated in a range of few years. This encourages developing a long-term monitoring of the benefits and negative impacts of the activity, based upon regular assessment.

On another hand, ACC refers to two main processes which concerns different temporal scales (Magnan, 2010a). The first process is the resilience ${ }^{4}$ of each one of the components of the destination. Indeed, as all future changes won't be predictable or controllable, then to be able to react will continue to be an important strategy for societies. Resilience then refers to relative short-term timeframes. But ACC also refers to anticipation. Yet, anticipation is based upon medium to long-term proactive approaches. And finally, ACC refers to a multitemporal scales approach: schematically, its process and strategy dimensions are linked to long term dynamics, when its state dimension is more correlated to resilience phenomenon.

We can conclude here that if a one-shot TCC assessment can be useful for making adjustment on the state of adaptation, only a monitoring process can support building and adjusting adaptive strategies. From this viewpoint, TCC approach is an interesting entry point for designing and implementing ACC.

\section{Conclusions}

As most climate change effects are both unavoidable and unpredictable, trying to implement sustainability principles constitutes a 'no regret' strategy in order to adapt to climate change. This implies that some already existing tools and frameworks can be useful for ACC. This is the case of Integrated Coastal Zone Management (ICZM), which principles participate to a long-term reduction of environmental and anthropogenic pressures on coastal areas. In such a context, and considering that TCC is a tool for implementing ICZM, it seems useful to question the relevance of TCC for starting adapting to climate change. Schematically, the hypothesis relies on the following reasoning: (i) TCC must be considered as a tool for reducing environmental and anthropogenic vulnerability; (ii) yet, reducing vulnerability to changes is the goal of ACC; (iii) therefore, implementing a TCC approach could reveal useful for tourism coastal territories to start implementing ACC.

This reasoning is based upon the hypothesis that TCC and ACC share some features: they are based upon a global and systemic approach, they are necessarily context-specific, and they require a dynamic conception. We also emphasised that TCC and ACC present two major differences: the former is a tool when the later is a concept; and the former is timeconstrained when the later could only be relevant at the crossroads of multiple temporal scales.

Finally, as the goal of the TCC approach is to draw up a diagnosis of the weaknesses and strengths of a territory in face of perturbations, it provides tangible elements to encounter the problem of 'decisions and actions freeze' due to the existence of uncertainties. Linking TCC

\footnotetext{
${ }^{4}$ Resilience can be defined for anthropogenic systems as the ability of groups or communities to cope with external stresses and disturbances as a result of social, political, and environmental change.
} 
and ACC shows that regardless the problem of climate change uncertainties, tools already exist to start doing something.

\section{References}

Blaikie P., Cannon T., Davis I., Wisner B., 1994. At risk: natural hazards, people's vulnerability and disaster. Routledge, London.

Cazes-Duvat V., Pesme J.-O., 2002. Etude de capacité de charge des plages des côtes ouest et sud de l'île de La Réunion. Synthesis report. $175 \mathrm{p}$.

Clarke A.L., 2002. Assessing the carrying capacity of the Florida Keys. Population and Environment, 23 (4), $405-$ 417.

Cocossis H., Mexa A., Collovini A., Parpairis A., Konstandoglou M., 2001. Defining, measuring and evaluating carrying capacity in european tourism destinations. Final report. Athens, $52 \mathrm{p}$.

Deprest F., 1997. Enquête sur le tourisme de masse : l'écologie face au territoire. Belin, Paris.

Duvat V., 2007. Les littoraux coralliens des petites îles de l'océan Indien (Mascareignes, Seychelles, Maldives). Institut Oceanographique (Ed.), Paris, 2 volumes.

Duvat V., 2008. L'intérêt d'une approche en termes de capacité de charge pour les gestionnaires : l'exemple de l'île de La Réunion (océan Indien). Proceedings of the international symposium "Les littoraux : subir, dire, agir" Lille, France, 16-18/01/2008.

Duvat V., Magnan A., 2009. Coastal vulnerability assessment in Djerba (Tunisia). In Özhan E. (Ed.): Proceedings of the Ninth International Conference on the Mediterranean Coastal Environment, MedCoast 2009, Middle East Technical University, Ankara, Turkey, vol. 1-2, 355-566.

Magnan A., 2009. La vulnérabilité des territoires littoraux au changement climatique : mise au point conceptuelle et facteurs d'influence. Analyses, Iddri's working paper, 01/2009, Paris, 30 p. [On line: http://www.iddri.org]

Magnan, A., 2010a, For a better understanding of adaptive capacity to climate change: a research framework. Analyses, Iddri's working paper, 2/2010, 26 p. [On line: http://www.iddri.org].

Magnan A., 2010b. Coastal tourism, climate change uncertainties and adaptation options. In Brebbia C.A., Pineda F.D. (Eds.): Sustainable Tourism IV, Proceedings of the Fourth international conference on sustainable tourism, WIT Press, Ashurst, Southampton, UK, 229-240.

Manning R., Wang B., Valliere W., Lawson S., Newman P., 2002. Research to estimate and manage carrying capacity of a tourist attraction: a study of Alcatraz island. Journal of Sustainable Tourism, 10 (5), 388-404.

Marzetti Dall'Aste Brandolini S., Mosetti R., 2005. Social carrying capacity of mass tourism sites: theoretical and practical issues about its measurement. FEEM working paper 144.2005, $10 \mathrm{p}$.

McCool S.F., Lime D.W., 2001. Tourism carrying capacity: tempting fantasy or useful reality? Journal of Sustainable Tourism, 9 (5), 372-388.

O'Reilly A.M., 1986. Tourism carrying capacity: concept and issues. Tourism Management, December, 254-258.

Pereira de Silva C., 2002. Beach carrying capacity assessment: how important is it? Journal of Coastal Research, 36, 190-197.

Pottier P., Chadenas C., Pouillaude A., Struillou J.-F., 2009. Evaluer la capacité d'accueil et de développement des territoires littoraux. Approche et méthode. Les cahiers des Pays de la Loire, 2, 35 p.

Saveriades A., 2000. Establishing the social tourism carrying capacity for the tourist resorts of the east coast of the Republic of Cyprus. Tourism Management, 21, 147-156.

Seidl I., Tisdell C.A., 1999. Carrying capacity reconsidered: from Malthus' population theory to cultural carrying capacity. Ecological Economics, 31, 395-408.

Smit, B., J. Wandel, 2006, Adaptation, adaptive capacity and vulnerability, Global Environmental Change, $16,282-292$

Solomon S., Plattner G.-K., Knutti R., Friedlingstein P., 2009. Irreversible climate change due to carbon dioxide emissions. Proceedings of the National Academy of Sciences (USA), 106 (6), 1704-1709.

\section{Acknowledgements}

The authors acknowledge both the European Commission (DG Research - CIRCE project - Climate change and impact research: the Mediterranean environment) and the Région lle de France (R2DS project) for their support. 